\title{
Die letzte Seite
}

Dankward Höntzsch

Endlich der max. 5 Euro kostende Fixateur...

Material:

- 4 Schrauben aus Edelstahl: 0,50 × 4=2,00€

- 1 Bambusstab: max 0,50€

- Je Schraube 2 gekreuzte Kabelbinder: 0,10 × 8 =0, $80 €$

Instrumente: für die Löcher bohren Maschine und Bohrer, passender Schraubenzieher, Kabelbinder-Spannzange, Seitenschneider

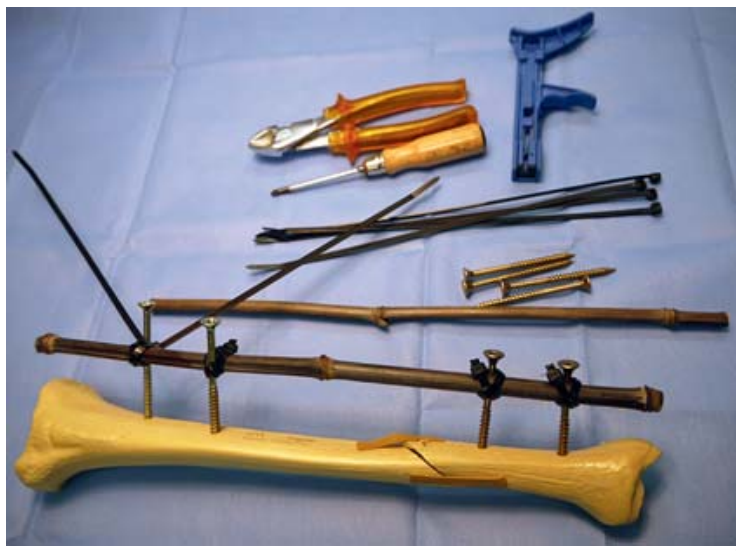

- Abb. 1 alles auf einen Blick am Modell: Tibia frakturiert, 4 Edelstahlschrauben 6 × 150 mm, Kreuzschlitz oder Torx, Bambusstab (hier besonders schöner schwarzer Bambus aus Südkorea - war umsonst), Kabelbinder, dafür Kabelbinderspanner nötig zum gut spannen, Seitenschneider

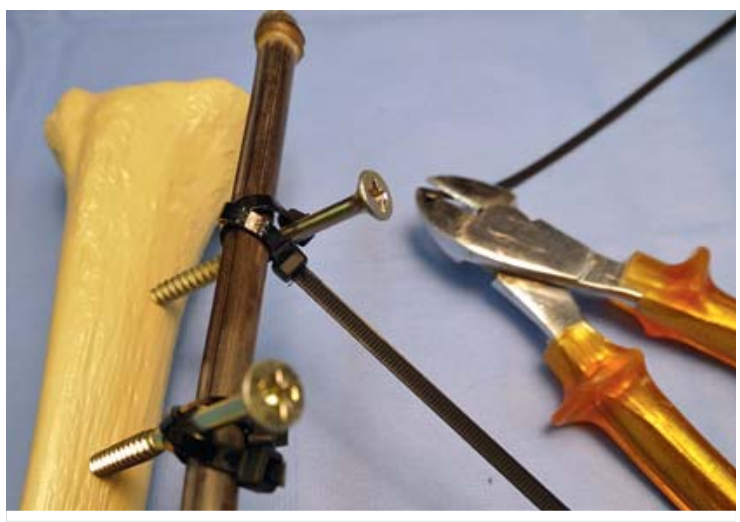

- Abb. 3 Überstehende Enden abschneiden.
Entwicklung und Labortests für die CE Markierung und FDA Zertifizierung im Entwicklungsinstitut Visionen in Tübingen.

Workshops und Kurse sind geplant (Kursgebühr voraussichtlich $10 €)$

Ohne Gewähr

D. Höntzsch

Korrespondenzadresse

Prof. Dr. Dankward Höntzsch

hoentzsch@t-online.de

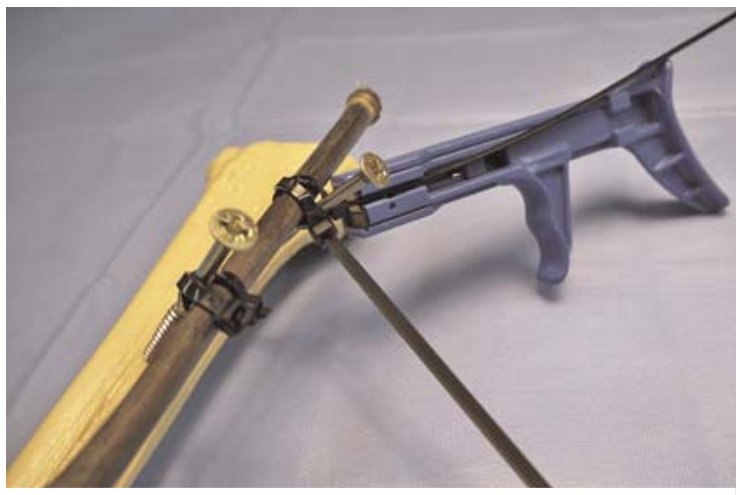

- Abb. 2 Zwei Kabelbinder müssen gekreuzt gespannt werden. Das war der technische Durchbruch! Tipp: mit den äußeren Schrauben anfangen dann schrittweise nacheinander immer mehr anspannen

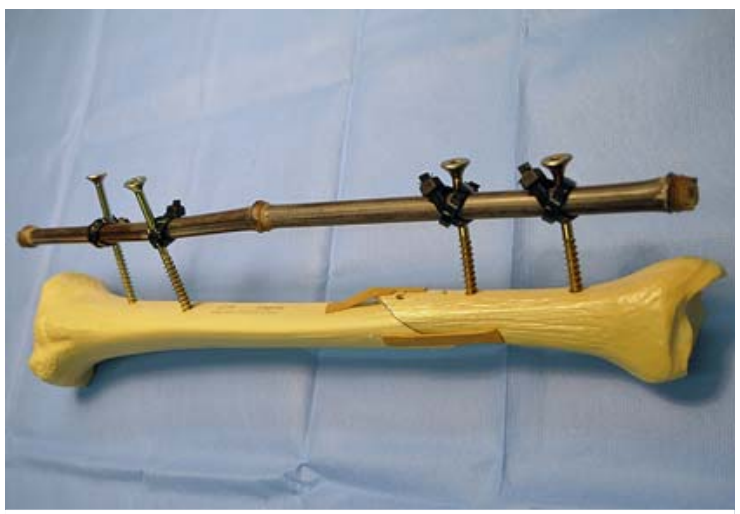

- Abb. 4 Fertig! 